\title{
Suplementação concentrada para bovinos de corte em sistema de integração lavoura e pecuária no período das águas
}

\author{
Concentrate supplementation to beef cattle raised in integrated crop and livestock during \\ rainy season
}

\begin{abstract}
ALONSO, Marcell Patachi ${ }^{1 *}$; MORAES, Eduardo Henrique Bevitori Kling de ${ }^{2}$ PINA, Douglas dos Santos ${ }^{2}$; PEREIRA, Dalton Henrique ${ }^{2}$; MOMBACH, Mircéia Angele ${ }^{2}$; GIMENEZ, Breno de Moura ${ }^{2}$; WRUCK, Flávio Jesus ${ }^{3}$
\end{abstract}

\footnotetext{
${ }^{1}$ Universidade Federal de Mato Grosso, Programa de Pós-Graduação em Ciência Animal, Pontes e Lacerda, Mato Grosso, Brasil.

${ }^{2}$ Universidade Federal de Mato Grosso, Zootecnia, Instituto de Ciências Agrárias, Departamento de Zootecnia, Sinop, Mato Grosso, Brasil.

${ }^{3}$ Embrapa Arroz e Feijão, Santo Antônio de Goiás, Goiás, Brasil.

*Endereço eletrônico para correspondência: pataki.alonso@yahoo.com.br.
}

\section{RESUMO}

Embora a produção de bovinos alimentados com suplementos concentrados seja crescente, sua aplicação em associação à sistemas de integração lavoura e pecuária ainda carece de mais estudos. Este trabalho teve o objetivo avaliar o desempenho produtivo de bovinos em pastagem de Brachiaria brizantha cv. Marandu, consumindo quatro diferentes suplementos, SM - mistura mineral, SE - suplemento energético, SEP - suplemento energético-protéico e SPE suplemento protéico-energético. Foram utilizados 100 novilhos não castrados, sendo 57 mestiços (Holandês x Nelore) e 43 da raça Nelore, com idade média de 15 meses e peso corporal médio de $281 \pm 31 \mathrm{~kg}$. A área experimental constituiu-se de quatro piquetes formados com B. brizantha cv. Marandu. O experimento foi estruturado segundo o esquema fatorial $(2 \times 4)$ distribuído em um delineamento inteiramente casualizado, onde foram avaliados dois grupos genéticos e quatro diferentes formulações de suplementos. A quantidade ofertada foi de $0,5 \mathrm{~kg} /$ animal/dia para SE, SEP e SPE, salvo o SM ofertado ad libitum. Houve diferença de grupo genético sobre a produção dos animais, sendo que os novilhos mestiços apresentaram melhor desempenho. A média de ganho de peso diário, ganho de peso total e peso corporal final, foram maiores nos animais que consumiram SE em relação ao SM e SPE. O SE, possibilita desempenho animal superior à SM e a SPE para bovinos em pastejo em sistema de integração lavoura e pecuária no período das águas. A recria de novilhos mestiços (Holandês $\mathrm{x}$ Nelore) no sistema integração lavoura e pecuária durante período das águas apresenta melhor desempenho comparado a recria novilhos Nelore.

Palavras-chave: desempenho animal, pastagem, recria

\section{SUMMARY}

Although the production of cattle fed concentrate supplement is growing, its application in association with integrated crop and livestock still needs further studies. This work was objective to evaluate the performance development of cattle grazing Brachiaria brizantha cv. Marandu, consuming four different supplements, MM - mix mineral, SE energy supplement, SEP - protein and energy supplement and SPE - energy protein and supplement. A total of 100 steers uncastrated, 57 crossbred (Holstein x Nelore) and 43 Nelore, with 15 months of average age and $280 \pm 31 \mathrm{~kg}$ of body weight. The experiment consisted of four paddocks formed by $B$. brizantha $\mathrm{cv}$. Marandu. The work was designed as factorial 
arrangement $(2 \times 4)$ in a completely randomized design, were evaluated two genetic groups and four different formulations of supplements. The quantity of supplements offer of 0.5 $\mathrm{kg}$ /animal/day for the SE, SEP and SPE, except the $\mathrm{MM}$ offered ad libitum. There was significant effect of genetic group on productive performance of animals, crossbred steers and that had better performance. The average daily and total gain weight, were higher in animals that consumed SE in relation to SM and SPE. The SE, allows animal performance superior to MS and SPE for grazing cattle in integrated crop and livestock during the rainy season. The rearing of crossbred steers (Holstein x Nelore) in integrated crop and livestock during the rainy presents better performance compared to recreate Nelore.

Keywords: animal performance, pasture, rearing

\section{INTRODUÇÃO}

O Brasil consolidou-se como maior exportador mundial de carne bovina ao final da primeira década do século 21 , o que conferiu ao país o título de maior fornecedor de alimentos desta origem frente às expectativas de aumento na demanda do mercado internacional.

Para a ampliação da capacidade produtiva da bovinocultura de corte nas áreas atualmente exploradas, técnicas como a integração de cultura de grãos à pecuária e a suplementação de animais em pastejo demonstram-se oportunas, apresentando-se como alternativa promissora para o desenvolvimento de sistemas de produção mais eficientes.

O sistema de integração lavoura e pecuária (ILP) contempla as características de melhora na qualidade do pasto e, manutenção desta por maior tempo possível, decorrente dos efeitos benéficos proporcionados pelos melhores atributos físicos, químicos e biológicos do solo (VILELA et al., 2003).
Quando contrastado aos sistemas de produção convencionais, a ILP promove maior conservação dos recursos ambientais, assegurando o uso racional das áreas agrícolas e de pastagens. Tais benefícios tornam-se evidentes pela redução da pressão de desmatamento de novas áreas e pela redução dos problemas ambientais originados por erosão e queimadas (GONÇALVES \& FRANCHINI 2007).

De modo inclusivo, a produção de grãos no sistema permite a utilização de produtos e resíduos na dieta animal sob a forma de suplementação alimentar concentrada em períodos de baixa produtividade e baixo valor nutricional do pasto, o que proporciona ao sistema maior eficiência de utilização de seus recursos.

O princípio da suplementação alimentar concentrada de animais criados à pasto se baseia no suprimento de suas exigências nutricionais, complementando valor nutritivo da forragem, sendo esta técnica fatível em qualquer período do ano atendendo à diferentes objetivos de produção.

Desta forma, objetivou-se avaliar o desempenho produtivos de bovinos de corte, Nelore e mestiços, na fase de recria, suplementados em pastagem com Brachiaria brizantha cv. Marandu, cultivada em sistema de ILP durante o período das águas.

\section{MATERIAL E MÉTODOS}

O experimento foi conduzido em uma propriedade particular localizada no município de Santa Carmem, região norte do Estado de Mato Grosso, durante o período das águas, compreendendo os meses de janeiro a abril do ano de 2010 . A área experimental encontra-se sob as 
coordenadas geográficas $12^{\circ} 03^{\prime} 52.07^{\prime}$, Sul e 55²1'16.92' 'Oeste.

O clima de Santa Carmem é, de acordo com a classificação de Köppen-Geiger, do tipo Am (clima de monção), ou seja, tropical chuvoso com um pequeno período de chuvas no mês mais seco. $\mathrm{O}$ município localiza-se no Planalto dos
Parecis, sendo o relevo homogêneo com pouca declividade e altitude média de 435,0m em relação ao nível do mar.

A área do sistema de ILP utilizado apresentou, durante cinco anos agrícolas, distintas culturas, sendo iniciado o experimento na época das águas do ano de 2009/10 (Tabela 1).

Tabela 1. Histórico da distribuição das culturas em função do ano agrícola e da época do ano

\begin{tabular}{lcc}
\hline \multirow{2}{*}{ Ano agrí́cola } & \multicolumn{2}{c}{ Época } \\
\cline { 2 - 3 } & Águas & Seca \\
\hline $2005 / 06$ & Soja $^{1}$ & Sorgo $^{3}+$ B. ruziziensis \\
$2006 / 07$ & Soja $^{1}$ & Milho $^{4}+$ B. ruziziensis \\
$2007 / 08$ & Arroz $^{2}$ & Milheto $^{5}+$ Sorgo $^{3}+$ B. ruziziensis \\
$2008 / 09$ & Soja $^{1}$ & Milho $^{4}+$ B. brizantha cv. Marandu \\
$2009 / 10$ & B. brizantha cv. Marandu & - \\
\hline${ }^{1}$ Precoce; ${ }^{2}$ Semeado em plantio direto; ${ }^{3}$ Pastejo; ${ }^{4}$ Safrinha; ${ }^{5}$ Semeado sobre o consórcio Sorgo $+B$. \\
ruziziensis que germinaram inadequadamente.
\end{tabular}

A área destinada à avaliação das variáveis do pasto e do desempenho produtivo dos animais apresentava dimensão total de 18,72 ha, subdividido em quatro piquetes de 4,68ha, delimitados internamente por cerca elétrica.

O pasto foi formado homogeneamente pela gramínea Brachiaria brizanta cv. Marandu, sendo sua implantação realizada no ano agrícola 2008/09, em consórcio à cultura de milho (Zea mays) dentro das técnicas preconizadas pelo sistema de ILP - Santa Fé. Após a colheita do grão o pasto foi manejado até o dia de início do período experimental, sendo realizada uma adubação de manutenção com $50 \mathrm{~kg}$ de $\mathrm{N} /$ ha dez dias após o início das atividades com intuito de proporcionar acréscimo na produção de massa de forragem.

O experimento foi conduzido através de lotação contínua, com taxa de lotação variável em função do ganho médio diário dos animais. Para avaliação de desempenho foram utilizados 100 novilhos não castrados, sendo 43 animais da raça Nelore e 57 animais mestiços (Nelore x Holandês), com idade média de 15 meses e peso corporal médio inicial de $281 \pm 31 \mathrm{~kg}$. Os animais foram distribuídos aleatoriamente em quatro lotes com pesos semelhantes. Ao início do experimento, todos os animais foram submetidos ao controle de endo e ectoparasitas e durante o período experimental, quando necessário, realizaram-se controles individuais dos animais que apresentaram infestações por miíases.

Os dados climáticos referentes ao período experimental foram mensurados, para temperatura, da estação automática pertencente ao Instituto Nacional de Meteorologia e, para precipitação, de um pluviômetro localizado a cerca de 100 $\mathrm{m}$ da área experimental (Tabela 2). 
Rev. Bras. Saúde Prod. Anim., Salvador, v.15, n.2, p.339-349 abr./jun., 2014 http://www.rbspa.ufba.br ISSN 15199940

Tabela 2. Valores médios diários das temperaturas máximas e mínimas, e precipitação pluviométrica média e total ao longo do período experimental

\begin{tabular}{llccc}
\hline \multirow{2}{*}{ Períodos } & \multicolumn{2}{c}{ Temperaturas Médias $\left({ }^{\circ} \mathrm{C}\right)^{1}$} & \multicolumn{2}{c}{ Precipitação $(\mathrm{mm})^{2}$} \\
\cline { 2 - 5 } & Máxima & Mínima & Média & Total \\
\hline Jan/Fev & 31,04 & 21,64 & 12,91 & 361,50 \\
Fev/Mar & 31,91 & 22,25 & 9,91 & 277,50 \\
Mar/Abr & 30,75 & 21,83 & 10,86 & 304,00 \\
\hline
\end{tabular}

Fonte: ${ }^{1}$ Instituto Nacional de Meteorologia; ${ }^{2}$ Pluviômetro de campo.

Foram avaliados quatro tratamentos compostos por um suplemento mineral (SM) e três suplementos concentrados (suplemento energético - SE; suplemento energético protéico - SEP; suplemento protéico energético - SPE) na alimentação de bovinos recriados em pastejo no período das águas (Tabela 3). O SE se caracterizou por possuir menos de $20 \%$ de $P B$ e não conter fonte protéica, SEP por possuir menos de $20 \%$ de PB e conter fonte protéica, e o SPE por ter mais de $20 \%$ de PB e conter fonte protéica.

Tabela 3. Composição percentual dos suplementos com base na matéria natural

\begin{tabular}{lcccc}
\hline \multirow{2}{*}{ Ingredientes } & \multicolumn{4}{c}{ Suplementos } \\
\cline { 2 - 5 } & SM & SE & SEP & SPE \\
\hline Mistura mineral $^{1}$ & 100,0 & 14,0 & 14,0 & 14,0 \\
Resíduo de feijão moído $^{\text {Grão de milheto moído }}$ & - & - & 17,7 & 43,1 \\
Uréia & - & 86,0 & 66,8 & 36,9 \\
\hline
\end{tabular}

${ }^{1}$ Suplemento mineral comercial.

Níveis de garantia: Cálcio 180,0g/kg; Sódio 120,0g/kg; Fósforo 85,0g/kg; Enxofre 15,0g/kg; Magnésio 2,0g/kg; Zinco 4500,0mg/kg; Cobre 1300,0mg/kg; Manganês 1150,0mg/kg; Flúor 830,0mg/kg; Cobalto $85,0 \mathrm{mg} / \mathrm{kg}$; Iodo $85,0 \mathrm{mg} / \mathrm{kg}$; Selênio $24,5 \mathrm{mg} / \mathrm{kg}$.

$\mathrm{O}$ arraçoamento dos animais ocorreu próximo as $10: 00 \mathrm{~h}$ com tempo gasto total de 30 minutos. A quantidade ofertada de suplemento concentrado foi de $0,5 \mathrm{~kg}$ de matéria natural/animal/dia para SE, SEP e SPE. Contudo, para o $\mathrm{SM}$, o ofertado aos animais foi ad libitum.

Após a pesagem inicial, os animais foram distribuídos em quatro lotes, aos quais foram alocados os tratamentos aleatoriamente, sendo 28 dias o intervalo entre as pesagens subsequentes. Os pesos dos animais foram mensurados, sem jejum prévio, sempre no mesmo horário do dia, com o objetivo de acompanhar o desempenho produtivo, durante e ao término do experimento. A fim de minimizar algum eventual efeito benéfico inerente a algum piquete, como uma possível variação na massa de matéria seca (MS) de forragem, procedeu-se o rodízio dos lotes de animais a cada 14 dias, mantendo-se o fornecimento do respectivo tratamento aos mesmos.

Ao início do experimento e sucessivamente a cada 10 dias, realizouse a coleta de amostras de massa de forragem através do corte de cinco áreas aleatórias de cada piquete experimental. Os cortes foram feitos a uma altura de 
0,10m do solo, delimitados por um quadrado metálico com dimensão de $0,50 \times 0,50 \mathrm{~m}$. Seguido o corte, as amostras foram pesadas e os valores registrados para posterior determinação da massa de forragem. Em seguida, o material de cada piquete foi homogeneizado, do qual foi coletado duas subamostras compostas por piquete, sendo, uma para determinação da composição bromatológica e massa total de forragem em $\mathrm{t}$ de $\mathrm{MS} / \mathrm{ha}$ e a outra fracionada para os componentes lâmina foliar verde, lâmina foliar seca, colmo verde e colmo seco, sendo a bainha e a inflorescência considerados como colmo, o que permitiu o conhecimento da composição bromatológica de cada componente.

Das amostras destinadas à estimativa da massa total de forragem foram calculados os percentuais de MS potencialmente digestível (MSpD) disponível aos animais. Os resultados foram obtidos por intermédio do resíduo insolúvel em detergente neutro, obtido após incubação ruminal in situ das amostras por 240 horas (CASALI et al. 2008).

As análises laboratoriais foram realizadas de acordo com descrições de Silva \& Queiroz (2002) com exceção das avaliações de FDN e FDA que seguiram os métodos descritos por Mertens (2002) e Van Soest \& Robertson (1985), respectivamente. A FDN indigestível (FDNi) foi obtida segundo recomendações de Casali et al. (2008) e os teores de nitrogênio insolúvel em detergente neutro (NIDN) e em detergente ácido (NIDA) foram obtidos conforme Licitra et al. (1996).

Os teores de carboidratos totais das amostras foram calculados segundo equação proposta por Sniffen et al. (1992), em que CT(\%) $=100-(\% \mathrm{~PB}+$ $\% \mathrm{EE}+\%$ Cinzas). Para os carboidratos não fibrosos (CNF) da forragem e do suplemento que não continha uréia na formulação, o cálculo foi realizado por meio da diferença entre CT e FDNcp. Já para os suplementos contendo uréia utilizou-se a equação proposta por Hall (2000).

Para estimativa de NDT ( $\%$ da MS) da forragem e dos suplementos, utilizou-se o modelo sugerido pelo NRC (2001).

$\mathrm{O}$ experimento foi estruturado segundo um esquema fatorial $(2 \times 4)$, sendo dois grupos genéticos e quatro suplementos, distribuído em um delineamento inteiramente casualizado (DIC) com período experimental de 84 dias, subdividido em três períodos de 28 dias (Tabela 4).

O peso corporal inicial foi utilizado como covariável no modelo estatístico para as variáveis em estudo e, no caso da não significância do mesmo, este parâmetro foi retirado do modelo e a análise foi realizada novamente.

As variáveis mensuradas foram submetidas à análise de variância e as médias de mínimos quadrados comparadas pelo teste " $t$ " adotando-se um nível de significância de 0,05. Para realização da análise variância foi utilizado o PROC GLM do programa computacional SAS (STATISTICAL ANALYSES SYSTEM, 2011).

O modelo estatístico utilizado para o experimento foi: $Y_{i j k}=\mu+S_{i}+G_{j}+$ $S_{i} * G_{j}+\beta *\left(P I_{i j k}-P I / n\right)+e_{i j k}$. Onde: $Y_{i j k}=$ resposta observada no animal $\mathrm{k}$, do grupo genético $\mathrm{j}$, consumindo suplemento $\mathrm{i} ; \mu=$ média geral observada; $S_{i}=$ efeito do suplemento i, i = (SM; SE; SEP; SPE); $G_{j}$ $=$ efeito do grupo genético $\mathrm{j}, \mathrm{j}=$ (Nelore; Mestiço); $S_{i} * G_{j}=$ efeito da interação entre suplemento e grupo genético; $\beta=$ coeficiente de inclinação do modelo linear; $P I_{i j k}=$ covariável peso corporal inicial; $P I / n=$ média geral do peso corporal inicial; $e_{i j k}=$ erro aleatório associado a cada observação. 
Rev. Bras. Saúde Prod. Anim., Salvador, v.15, n.2, p.339-349 abr./jun., 2014 http://www.rbspa.ufba.br ISSN 15199940

Tabela 4. Média da composição nutricional dos suplementos e do pasto

\begin{tabular}{|c|c|c|c|c|c|}
\hline \multirow{2}{*}{ Item } & \multicolumn{4}{|c|}{ Suplementos } & \multirow{2}{*}{ Pastc } \\
\hline & SM & SE & SEP & SPE & \\
\hline $\mathrm{MS}^{1}(\%)$ & 98,86 & 90,12 & 90,33 & 90,87 & 25,82 \\
\hline $\mathrm{MO}^{2,16}$ & 0,76 & 83,33 & 83,24 & 83,19 & 90,78 \\
\hline $\mathrm{MM}^{3,16}$ & 99,24 & 16,67 & 16,76 & 16,81 & 9,22 \\
\hline $\mathrm{PB}^{4,16}$ & - & 12,42 & 18,41 & 33,27 & 7,30 \\
\hline NIDN $^{5,17}$ & - & 22,89 & 21,42 & 18,68 & 35,76 \\
\hline NIDA $^{6,17}$ & - & 6,06 & 7,27 & 8,83 & 17,77 \\
\hline $\mathrm{EE}^{7,16}$ & - & 4,28 & 3,69 & 2,72 & 1,46 \\
\hline $\mathrm{CT}^{8,16}$ & - & 66,52 & 63,76 & 57,98 & 82,02 \\
\hline $\mathrm{CNF}^{9,16}$ & - & 54,17 & 52,17 & 47,64 & 17,79 \\
\hline $\mathrm{FDN}^{10,16}$ & - & 12,85 & 12,16 & 10,81 & 67,93 \\
\hline FDNcp $^{11,16}$ & - & 12,35 & 11,67 & 10,36 & 64,23 \\
\hline $\mathrm{FDNi}^{12,16}$ & - & 10,80 & 9,56 & 7,48 & 32,38 \\
\hline $\mathrm{FDA}^{13,16}$ & - & 6,58 & 7,16 & 7,80 & 35,75 \\
\hline $\mathrm{LIG}^{14,16}$ & - & 1,74 & 1,63 & 1,42 & 6,11 \\
\hline $\mathrm{NDT}^{15}$ & - & 72,99 & 71,23 & 66,72 & 46,33 \\
\hline
\end{tabular}

${ }^{1}$ Matéria seca; ${ }^{2}$ Matéria orgânica; ${ }^{3}$ Matéria mineral; ${ }^{4}$ Proteína bruta; ${ }^{5}$ Nitrogênio insolúvel em detergente neutro; ${ }^{6}$ Nitrogênio insolúvel em detergente ácido; ${ }^{7}$ Extrato etéreo; ${ }^{8}$ Carboidratos totais; ${ }^{9}$ Carboidratos não fibrosos; ${ }^{10}$ Fibra em detergente neutro; ${ }^{11}$ Fibra em detergente neutro corrigida para cinzas e proteína; ${ }^{12}$ Fibra em detergente neutro indigestível; ${ }^{13}$ Fibra em detergente ácido; ${ }^{14}$ Lignina; ${ }^{15}$ Nutrientes digestíveis totais; ${ }^{16} \%$ da MS; ${ }^{17} \%$ do N total.

\section{RESULTADOS E DISCUSSÃO}

As massas médias de forragem total (MFT), forragem potencialmente digestível (MFpd), lâmina foliar verde (MFV), lâmina foliar seca (MFS), colmo verde (MCV) e colmo seco (MCS) do pasto foram de 6,$19 ; 4,14$; 2,$05 ; 0,55 ; 2,96$ e 0,62 t de $\mathrm{MS} / \mathrm{ha}$, respectivamente (Figura 1).

A quantidade de MFT ocorreu, em grande parte, em função da adubação nitrogenada de manutenção realizada ao início das atividades, assim como pelo efeito residual dos fertilizantes aplicados no solo das culturas de grãos, como soja e milho, com o qual o pasto foi implantado em consórcio na área experimental do sistema de ILP (Tabela 1).

Segundo os dados médios obtidos ao longo do período experimental (Figura 1), os valores observados de MFT encontraram-se acima do limite de
$2.000 \mathrm{~kg} / \mathrm{ha}$, valor este representativo à produtividade limite para que não ocorra restrição no consumo de forragem (MINSON, 1990). Adicionalmente, Euclides et al. (1998) sugerem valores de massa seca total acima de $2.500 \mathrm{~kg} / \mathrm{ha}$, em função de que em gramíneas de clima tropical ocorre grande proporção de hastes e de material morto na estrutura do dossel forrageiro o que culminaria negativamente no consumo da forragem pelos animais

No presente estudo, o percentual de $\mathrm{MSpD}$ variou de um valor mínimo de $64,80 \%$ à um máximo de $69,17 \%$ da MFT ao longo dos períodos, sendo a MFpd média correspondente a 4,14t/ha, o que determinou um considerável estoque de energia potencialmente disponível. Tais resultados podem ser atribuídos a manutenção de um percentual considerável de massa de forragem verde (MFV e MCV) na composição da MFT. 


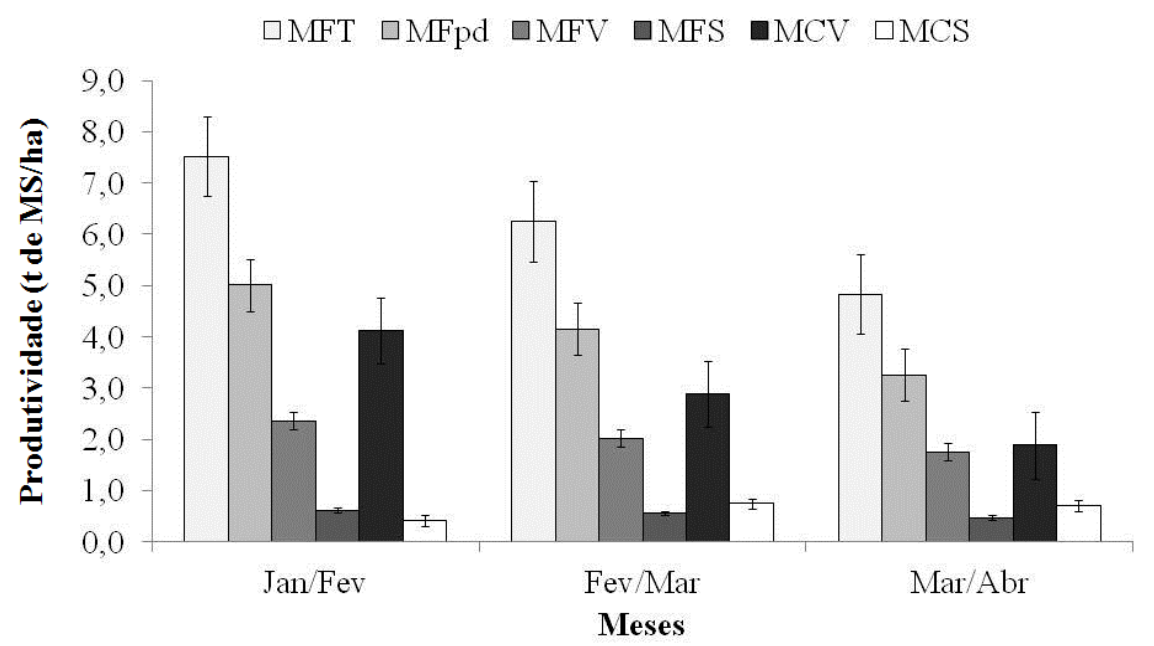

MFT: massa de forragem total; MFpd: massa de forragem potencialmente digestível; MFV: massa de lâmina foliar verde; MFS: massa de lâmina foliar seca; MCV: massa de colmo verde; e MCS: massa de colmo seco.

Figura 1. Valores médios de massa de forragem nos períodos experimentais

Considerações acerca de massa, proporções e da qualidade nutricional dos segmentos morfológicos do componente vegetal possuem grande importância devido à influência sobre o consumo de MS de pasto e, consequentemente, sobre o desempenho dos animais em pastejo (SANTOS et al. 2004). Situações em que não haja limitações de massa de forragem, maior será a seletividade do animal que opta no momento do pastejo por selecionar porções mais nutritivas (lâminas foliares verdes) em detrimento aos colmos e ao material senescente e morto. Assim, a quantidade ótima de tecidos vivos no pasto desempenha um papel importante na resposta produtiva dos animais.

Os resultados das massas dos segmentos da forragem ( $\mathrm{t}$ de MS/ha) apresentaram, para MFV e MFS, manutenção ao longo dos períodos experimentais. Para MFV, tal comportamento é justificado pelo favorecimento das condições climáticas ao desenvolvimento vegetativo da forrageira (Tabela 2). Já para MFS, a não evidência de grandes variações possivelmente tenha ocorrido pelo consumo desta fração concomitantemente ao consumo de lâminas foliares verdes como descrito por Euclides et al. (1992), em que $81,7 \%$ do material coletado via fístula esofágica foi composto por folhas (verdes e secas).

Os valores de MCV neste estudo foram bastante expressivos em todo o período experimental, perfazendo $47,82 \%$ da MFT. Contudo, ainda que a MCS tenha apresentado aumento de seu valor ao longo dos períodos, sua participação perfez apenas $10,02 \%$ da MFT. A grande produção de colmos foi devida, provavelmente, por tratar-se de um pasto de primeiro ano, com alto potencial de crescimento.

$\mathrm{O}$ teor de PB do pasto (Tabela 4) apresentou-se superior ao valor de 7\% predito por Poppi \& McLennan (1995) como mínimo para adequada atividade microbiana no ambiente ruminal, não sendo, portanto, fator restritivo para o desenvolvimento dos microrganismos ruminais, bem como, para a diminuição do consumo de forragem.

Contudo, ainda que este nível encontrese acima do mínimo supracitado, a alta 
degradação da $\mathrm{PB}$ do pasto no período das águas, pode provocar perda de nitrogênio no rúmem sob a forma de amônia, gerando déficit protéico quando da exigência de elevados ganhos (POPPI \& McLENNAN, 1995). O que permite pressupor que, melhores desempenhos por parte dos animais podem ser evidenciados quando supridas estas deficiências, ainda que no período das águas, via suplementação da dieta.
Para os valores de ganho de peso médio diário (GMD) dos animais e ganho de peso total (GPT), a covariável peso corporal inicial não se apresentou significativa $(\mathrm{P}>0,05)$. Também não foi observado interação $(\mathrm{P}>0,05)$ entre $\mathrm{o}$ grupo genético e os suplementos estudados. Porém, o grupo genético influenciou $(\mathrm{P}<0,05)$ o GMD, GPT e peso corporal final, os quais foram superiores para os animais mestiços em relação aos animais Nelore (Tabela 5).

Tabela 5. Desempenho de bovinos Nelore e mestiços alimentados com suplemento mineral e concentrado em sistema de integração lavoura e pecuária

\begin{tabular}{|c|c|c|c|c|c|c|c|c|c|c|}
\hline \multirow{2}{*}{ Item } & \multicolumn{2}{|c|}{ GG } & \multirow{2}{*}{ Valor-P } & \multicolumn{4}{|c|}{ Suplementos (SP) } & \multirow{2}{*}{ Valor-P } & \multirow{2}{*}{$\begin{array}{l}\text { CV } \\
(\%)\end{array}$} & \multirow{2}{*}{ GGxSP } \\
\hline & $\mathrm{N}^{1}$ & $\mathrm{M}^{2}$ & & $\mathrm{SM}^{3}$ & $\mathrm{SE}^{4}$ & $\mathrm{SEP}^{5}$ & $\mathrm{SPE}^{6}$ & & & \\
\hline $\mathrm{GMD}^{7}$ & $0,616 \mathrm{~b}$ & $0,671 \mathrm{a}$ & 0,0274 & $0,625 b$ & $0,698 \mathrm{a}$ & $0,655 \mathrm{ab}$ & $0,597 \mathrm{~b}$ & 0,0338 & 17,73 & 0,2469 \\
\hline $\mathrm{GPT}^{8}$ & $51,74 b$ & $56,40 \mathrm{a}$ & 0,0272 & $52,48 b$ & $58,64 a$ & $55,00 \mathrm{ab}$ & $50,19 b$ & 0,0341 & 17,74 & 0,2461 \\
\hline $\mathrm{PCF}^{9}$ & $331,35 b$ & $335,72 \mathrm{a}$ & 0,0459 & $331,86 b$ & $338,08 \mathrm{a}$ & $334,51 \mathrm{ab}$ & $329,70 b$ & 0,0358 & 2,92 & 0,2750 \\
\hline
\end{tabular}

Os maiores ganhos observados nos animais mestiços possivelmente foram decorrentes do efeito da heterose. A superioridade evidenciada neste grupo genético corrobora as descrições de Alencar et al. (1995), de que os bovinos de corte cruzados quando comparados aos animais puros, em geral, apresentam melhores características de crescimento em sistemas de produção a pasto.

Neste experimento, o bom potencial produtivo dos animais mestiços também associasse ao sistema de produção de ILP, pois permitiu observar baixa infestação parasitária nos animais, em decorrência à interrupção do ciclo biológico (fase ambiental) obtido pela rotação entre culturas na área experimental. Tal efeito, possivelmente tenha permitido melhora das condições ambientais a ambos os grupos genéticos.
Contudo, aos animais mestiços, as expressões das características produtivas tornaram-se mais evidentes.

Observaram-se diferenças significativas quanto ao GMD e ao GPT entre o tratamento $\mathrm{SE}$ quando comparado ao SM e SPE $(\mathrm{P}<0,05)$, entretanto para SEP não se evidenciou diferença $(\mathrm{P}>0,05)$.

Quando considerado os resultados de GMD e GPT para SEP, não se observou diferenças significativas entre quaisquer outros tratamentos $(\mathrm{P}>0,05)$.

Os valores de desempenho e peso corporal final apresentaram-se superiores ao lote que consumiu SE em relação ao SM e SPE. Em contraste aos resultados deste experimento, Moraes et al. (2006) observaram que o desempenho de animais sob o consumo de SE não apresentou diferença em relação ao SM. 
No entanto, quando comparado ao SEP e SPE, o SE promoveu o pior desempenho. Segundo os autores, este comportamento indica que o fornecimento de suplementos energéticos não propicia aporte de $\mathrm{N}$ necessário para potencializar o ganho de peso de animais em regime de pastejo durante o período das águas.

Contudo, a justificativa acima não se aplica a este experimento, em virtude de que o SE possivelmente tenha propiciado o $\mathrm{N}$ necessário para $\mathrm{o}$ aumento da resposta dos animais, isto por que o milho, ingrediente utilizado por Moraes et al. (2006) como fonte energética, possui uma fração protéica de baixa degradação ruminal ( $\alpha$-zeína), conferindo a este ingrediente uma proteína de baixa qualidade quando comparada ao milheto (ingrediente deste estudo). Adicionalmente, o grão de milheto quando comparado ao grão de milho, possui a característica de permitir um aumento na digestibilidade aparente total do amido, devido ao aumento na digestibilidade intestinal deste componente (GONÇALVES et al., 2010).

Para gramíneas tropicais, Malafaia et al. (2003) enfatizaram a limitada produção da proteína microbiana pela deficiência de substratos prontamente fermentescíveis. Os autores destacaram a evidente melhora no desempenho de animais consumindo alimentos energéticos devido ao suprimento de carboidratos de rápida fermentação, permitindo aumento no fluxo de proteína microbiana para o intestino delgado.

Da mesma forma, Dewhurst et al. (2000) destacaram que a inclusão moderada de amido na dieta promoveria benefícios à microbiota ruminal, através do aumento no substrato e na taxa de crescimento de bactérias associadas à fase líquida.
Todavia, salienta-se a possibilidade de interações associativas negativas com a utilização de suplementos energéticos em detrimento ao consumo de pasto, como descrito por Mieres (1997). No entanto, para animais em pastejo em gramíneas tropicais, o consumo de forragem não é afetado pela suplementação energética quando a quantidade de suplemento consumido não supera $0,2 \%$ de peso vivo (MALAFAIA et al., 2003).

Desta forma, no presente experimento, as melhores respostas evidenciadas pela suplementação energética utilizada $(0,16 \%$ do peso vivo), permite inferir que o melhor desempenho dos animais não esteve associado a um possível efeito substitutivo do suplemento sobre o consumo de forragem.

Em outro experimento, realizado na mesma área avaliada neste estudo, Cobucci et al. (2007) evidenciaram resultados inferiores (5,4@/ha - quatro meses) quando comparado a este trabalho (7,2@/ha - três meses). Destaca-se que ambos os experimentos utilizaram animais em pastejo. Entretanto, Cobucci et al. (2007) fizeram uso somente de suplementação mineral o que possivelmente tenha contribuído para a menor produtividade. Destarte, visualizam-se bons rendimentos produtivos na assimilação do sistema de ILP, sobretudo quando da associação deste à técnica de suplementação concentrada.

A suplementação energética composta de grão de milheto moído e mistura mineral, possibilita desempenho animal superior à suplementação mineral e a suplementação protéico-energética para bovinos em pastejo em sistema de integração lavoura e pecuária no período das águas.

Novilhos mestiços (Nelore x Holandês), recriados em sistema de integração lavoura e pecuária no período das águas 
Rev. Bras. Saúde Prod. Anim., Salvador, v.15, n.2, p.339-349 abr./jun., 2014 http://www.rbspa.ufba.br ISSN 15199940

apresentam melhores desempenhos produtivos comparados a novilhos Nelore.

\section{AGRADECIMENTOS}

Ao pesquisador da Embrapa Arroz e Feijão, Dr. Tarcísio Cobucci, pelo projeto de ILP em desenvolvimento no Estado de Mato Grosso e pelo apoio ao desenvolvimento deste experimento.

\section{REFERÊNCIAS}

ALENCAR, M.M.; BARBOSA, P.F.; TULLIO, R.R.; CORRÊA, L.A. Peso à desmama de bezerros da raça Nelore e cruzados Canchim x Nelore e Marchigiana x Nelore. Revista da Sociedade Brasileira de Zootecnia, v.24, n.6, p.917-925, 1995.

CASALI, A.O.; DETMANN, E.; VALADARES FILHO, S.C.; PEREIRA, J.C.; HENRIQUES, L.T.; FREITAS, S.G.; PAULINO, M.F. Influência do tempo de incubação e do tamanho de partículas sobre os teores de compostos indigestíveis em alimentos e fezes bovinas obtidos por procedimentos in situ. Revista

Brasileira de Zootecnia, v.37, n.2, p.335-342, 2008.

COBUCCI, T.; WRUCK, F.J.; KLUTHCOUSCKI, J.; MUNIZ, L.C.; MARTHA JUNIOR, G.B.; CARNEVALLI, R.A.; TEIXEIRA, S.R.; MACHADO, A.A.; TEIXEIRA NETO, M.L. Opções de integração lavoura-pecuária e alguns de seus aspectos econômicos. Informe Agropecuário, v.28, n.240, p.64-79, 2007.
DEWHURST, R.J.; DAVIES, D.R.; MERRY, R.J. Microbial protein supply from the rumen. Animal Feed Science and Technology, v.85, p.1-21, 2000.

EUCLIDES, V.P.B.; MACEDO, M.C.M.; OLIVEIRA, M.P. Avaliação de diferentes métodos de amostragem (para se estimar o valor nutritivo de forragens) sob pastejo. Revista Brasileira de Zootecnia, v.21, n.4, p.691-702, 1992.

EUCLIDES, V.P.B.; EUCLIDES FILHO, K.; ARRUDA, Z. J.

Desempenho de novilhos em pastagem de Brachiaria decumbens submetidos a diferentes regimes alimentares. Revista Brasileira de Zootecnia, v.27, n.2, p.246-254, 1998.

GONÇALVES, S.L.; FRANCHINI, J.C. Integração Lavoura-Pecuária. Circular Técnica. Londrina: Embrapa Soja, n.44, 2007. Disponível em:

$<$ http://garoupa.cnpso.embrapa.br/downlo $\mathrm{ad} /$ cirtec/circtec44.pdf $>$. Acesso em: 12 fev. 2013.

GONÇALVES, J.R.S.; PIRES, A.V.; SUSIN, I.; LIMA, L.G.; MENDES, C.Q.; FERREIRA, E.M. Substituição do grão de milho por grão de milheto em dietas contendo silagem de milho ou silagem de capim-elefante na alimentação de bovinos de corte. Revista Brasileira de Zootecnia, v.39, n.9, p.2032-2039, 2010.

HALL, M.B. Calculation of nonstructural carbohydrate content of feeds that contain non protein nitrogen. Florida: University of Florida, p. A-25, Apr. 2000. (Bulletin, 339).

LICITRA, G.; HERNANDES, T.M.; Van SOEST, P.J. Standardization of procedures for nitrogen fractionation of ruminants feeds. Animal Feed Science and Technology, v.57, p.347-358, 1996. 
Rev. Bras. Saúde Prod. Anim., Salvador, v.15, n.2, p.339-349 abr./jun., 2014 http://www.rbspa.ufba.br ISSN 15199940

MALAFAIA, P.; CABRAL, L.S.; VIEIRA, R.A.M.; COSTA, R.M.; CARVALHO, C.A.B. Suplementação protéico-energética para bovinos criados em pastagens: Aspectos teóricos e principais resultados publicados no Brasil. Livestock Research for Rural Development, v.15, n.12, 2003.

MERTENS, D.R. Gravimetric determination of amylase-treated neutral detergent fibre in feeds with refluxing beakers or crucibles: collaborative study. Journal of AOAC International, v.85, p.1217-1240, 2002.

MIERES, J.M. Tipo de suplemento y su efecto sobre el forraje. In: MARTINS, D.V. Suplementacion estrategica para el engorde de ganado. Montevideo : Dpto. Producción Animal, INIA, 1997. p.11-16. (Serie Tecnica, 83).

\section{MINSON, D.J. Forage in ruminant} nutrition. San Diego: Academic Press, 1990. 483p.

MORAES, E.H.B.K.; PAULINO, M.F.; ZERVOUDAKIS, J.T.; VALADARES FILHO, S.C.; CABRAL, L.S.; DETMANN, E.; VALADARES, R.F.D.; MORAES, K.A.K. Associação de diferentes fontes energéticas e protéicas em suplementos múltiplos na recria de novilhos mestiços sob pastejo no período da seca. Revista Brasileira de Zootecnia, v.35, n.3, p.914-920, 2006.

NATIONAL RESEARCH COUNCIL NRC. Nutrient requeriments of beef cattle. 7.ed. Washington: National Academic Press, 2001. 242p.

POPPI, D.P.; McLENNAN, S.R. Protein and energy utilization by ruminants at pasture. Journal of Animal Science, v.73, p.278-290, 1995.
SANTOS, E.D.G.; PAULINO, M.F.; QUEIROZ, D.S.; VALADARES FILHO, S.C.; FONSECA, D.M.; LANA, R.P. Avaliação de pastagem diferida de Brachiaria decumbens Stapf. 1. Características químicobromatológicas da forragem durante a seca. Revista Brasileira de Zootecnia, v.33, n.1, p.203-213, 2004.

SILVA, D.J.; QUEIROZ, A.C. Análise de alimentos: métodos químicos e biológicos. 3.ed. Viçosa: UFV, 2002. $235 \mathrm{p}$.

SNIFEN, C.J.; O'CONNOR, J.D.; VAN SOEST, P.J.; FOX, D.G.; RUSSELL, J.B. A net carbohydrate and protein system for evaluating cattle diets: II. Carbohydrate and protein availability. Journal of Animal Science, v.70, p.3562-3577, 1992.

STATISTICAL ANALYSIS SYSTEM. SAS/STAT user's guide. Version 9.3. Cary: SAS Institute inc., 2011.

VAN SOEST, P.J.; ROBERTSON, J.B. Analysis of forages and fibrous foods. Ithaca: Cornell University, 1985. 202p.

VILELA, L.; MACEDO, M.C.M.; MARTHA JÚNIOR, G.B.; KLUTHCOUSKI, J. Benefícios da Integração lavoura e pecuária. In: KLUTHCOUSKI, J.; STONE, L.F.; AIDAR, H. (Ed.). Integração lavoura e pecuária. Santo Antônio de Goiás: EMBRAPA-CNPAF, 2003, p.143-170.

Data de recebimento: 21/08/2013

Data de aprovação: 21/05/2014 